\title{
Design, Synthesis and Antimicrobial Activities Evaluation of 1, 3 Thiazine Derivatives
}

\section{Khan Sana $^{1 *}$, Singh Gurdeep ${ }^{2}$ and GN Darwhekar ${ }^{1}$}

${ }^{1}$ Acropolis Institute of Pharmaceutical Education and Research, Indore, MP, India

${ }^{2}$ School of Pharmaceutical Sciences, Lovely Professional University, Phagwara,

Punjab, India

*Corresponding Author: Khan Sana, Acropolis Institute of Pharmaceutical

Education and Research, Indore, MP, India.
Received: April 21, 2021

Published: June 23, 2021

(C) All rights are reserved by Khan Sana., et al.

\section{Abstract}

Some novel 30 derivatives of 1, 3 thiazine have been designed for Computational studies. This derivatives of 1,3 thiazine were subjected to molecular docking studies against $E$. coli Glucosamine -6 P Synthase in Complex with Fructose -6 P (PDB ID- 4 AMV) and Crystal structure of Peptide deformylase from Staphylococcus Aureus Complex with Actinonin (PDB ID- 1Q1Y) using Molegro Virtual Docker software. On the basis of docking results 10 derivatives of thiazine were selected and synthesized by the condensation of 2-hydroxy-3- nitro5-chlorochalcones with thiourea and phenylthiourea in ethanol containing aqueous $\mathrm{KOH}$ solution. All synthesized compound have been screened for in-vitro evaluation of antimicrobial activities by agar plate techniques. The results indicated that all the synthesized 1, 3 thiazine derivatives shows considerable antimicrobial activities. This study suggested that 1, 3-thiazine derivatives founded to have potent antimicrobial activity against the selected pathogenic organisms and posses more antimicrobial activities on gram negative (E. coli) bacteria than gram positive bacteria (S. aureus). Keywords: 1, 3 thiazine, molecular docking, analysis, characterization, antimicrobial activities, thiourea, phenyl thiourea, gram negative bacteria.

Keywords: 1, 3 Thiazine; Molecular Docking; Analysis; Characterization; Antimicrobial Activities; Thiourea; Phenyl Thiourea; Gram Negative Bacteria

\section{Introduction}

In medicinal chemistry, pharmacology and biotechnology, the process by which drugs are discovered and designed is known as Drug Discovery. The process of drug discovery involves the identification of candidates, synthesis, characterization, screening and assays for therapeutic efficiency.

The drug discovery process increased in intensity because of the major screening and chemical synthetic effort in the pharmaceutical industry in worldwide industrialized countries. Despite understanding biological system and advance in technology, the drug discovery is still a long process with low rate of new therapeutic discovery. [1].

\section{Steps of drug discovery}

The drug discovery involves following steps:

- Screening of new compound

- Lead optimization

- Natural compounds mimicking

- Clinical development. 
Organic chemistry play an important role in modern science and has wide varieties applications in different fields since many research has been going on to synthesize new organic compounds and derivatives of naturally occurring ones.

Heterocyclic chemistry research encompasses almost half of the organic chemistry research throughout the world. A huge amount of bioactive organic compounds that contain heterocyclic frameworks play a vital part in the medicinal field.

It is commonly reported that heterocycles having sulphur or nitrogen atoms or both of them are the general features present in the structures of most of the pharmaceutical and natural compounds $[2,3]$. They also act as multidentate ligands for different metals due to the presence of nitrogen and sulfur atoms and are thus used extensively in coordination chemistry to obtain new frameworks with potential bioactivity [3]. According to Joshi., et al. it has also been identified that several heterocyclic compounds in the developmental phase have the potential to be part of new drugs and also play an important role in modern drug discovery [4].

\section{Antimicrobial agents}

Antimicrobial Agents are agents that kill microorganisms or stop their growth. Antimicrobial medicines can be grouped according to the microorganisms they act primarily against. For example, antibiotics are used against bacteria and antifungals are used against fungi. They can also be classified according to their function. Agents that kill microbes are called microbicidal, while those that merely inhibit their growth are called biostatic. The use of antimicrobial medicines to treat infection is known as antimicrobial chemotherapy, while the use of antimicrobial medicines to prevent infection is known as antimicrobial prophylaxis $[5,6]$.

Type of antimicrobial drugs

- Antibacterial drugs

- Antifungal drugs

- Antiviral drugs

- Anti-helminth drugs.

\section{Antibacterial agents}

The discovery of antibiotics has been regarded as one of the most significant medical achievements of the twentieth century.
Antibiotics have saved millions of lives and enabled important medical procedures, including surgery and cancer chemotherapy. The emergence and spread of antibacterial resistance in all geographical areas; including bacteria that cause hospital and community-acquired infections is however jeopardizing the effectiveness of these potentially life-saving treatments. The threat includes the spread of multidrug-resistant bacteria and infections with no therapeutic options have been reported. The rise in resistance not only impedes the ability to treat bacterial infections in humans and animals but has broader societal and economic effects that ultimately threaten achievement of the Sustainable Development Goals. This situation requires urgent, coordinated action at global, regional and national levels. Resistance is a natural phenomenon, and it is inevitable that it will develop to all antibiotics at some time. As misuse and overuse of antibiotics accelerate the development of resistance, antibiotics should be used more responsibly and new antibacterial treatments should be developed to counteract emerging resistance. However, there are challenges which are both; 'scientific' for the discovery of new antibiotics, and 'economic' for ensuring investment into research and development $[7,8]$.

Most of the new antibiotic classes; however, target Gram-positive bacteria, while the major challenge is to find new antibiotics against Gram-negative bacteria. These are identified as a critical priority by WHO on its priority pathogens list for R\&D of new antibiotics. Because of the complexity of the Gram-negative cell wall, discovery of novel antibiotics that can permeate this barrier and stay inside the bacterium is very challenging. The lack of new, quality lead chemicals to test against Gram-negative bacteria is another major impediment to discovery. Recently, drug resistance due to the extensive abuse and over-use of antibiotics has become an increasingly serious problem, making the development of alternative antibiotics a very urgent issue [9].

\section{Thiazine}

Thiazine is an organic compound containing a ring of four carbon, one nitrogen and one sulfur atom. There are three isomers of thiazine, 1, 2-thiazine, 1, 3-thiazine, and 1,4-thiazine, which differ by the arrangement of the nitrogen and sulfur atoms in the ring. They arefound to be fairly stable. Thiourea has been used in the synthesis of heterocyclic rings containing nitrogen and sulphur. 


\section{Structure of thiazine}

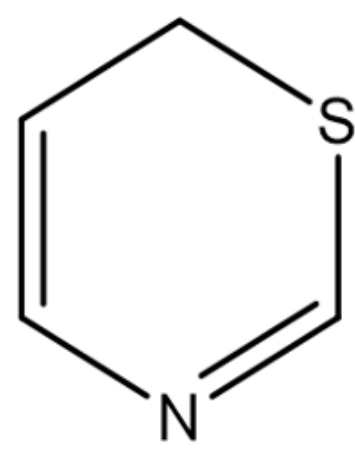

\section{1, 3- Thiazine}

Figure a

The thiazines possess a nitrogen and sulphur atoms in a six member ring (Figure), that is believed to be important for their antifungal, anticonvulsant, and antiviral activities. The uniqueness and resourcefulness of the simple thiazine chemical structure and easy availability make thiazines and their derivatives amongst the most gifted sources of bioactive compounds. Thiazine is a heterocyclic compound having one nitrogen and sulphur atom at varied positions in the six membered ring exist as 1,$2 ; 1,3 ; 1,4$-thiazines and subsequently their derivatives [10].

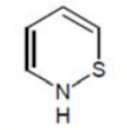

1.2-Thiazine

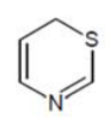

1,3-Thiazine

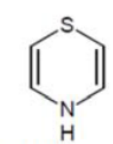

1, 4-Thiazine

\section{Figure b}

Biological activities of thiazine and benzothiazine derivatives

Heterocyclic thiazine and benzothiazine compounds are a crucial part of medicinal organic chemistry due to their useful medicinal properties. The largely unexplored heterocyclic compounds like thiazines possess a variety of pharmacological activities, rang- ing from antitumor, antipsychotic and anti-inflammatory properties on the one hand, while on the pathogenic side, they are equally important due to their antibacterial, antitubercular, antifungal, antiviral and antiprotozoal activities.

Thus, thiazine compounds display a wide range of beneficial properties [11]. Antimicrobial Activities Phenothiazines and their novel derivatives exhibit valuable biological activities both in vivo and in vitro. These compounds show good results against various diseases caused by bacteria, viruses, fungi, mollusca, or protozoa. The activities of these compounds were examined by applying them on various organisms such as mammals infected with pathogenic bacteria and viruses, cell lines, etc. [12]. The 1,3-thiazine moiety is the functional part of cephalosporins that are the $\beta$-lactam antibiotics, active against most Gram positive and a number of Gram negative pathogenic bacteria. Cephalosporins have a similar mode of action like penicillins and have an identical $\beta$-lactam ring, however, there are more atoms at the side rings [13]. Most of the penicillin-resistant bacteria are sensitive to cephalosporins, although there are some exceptions [13]. Bacterial resistance is a common problem to cephalosporins, for example the enteric bacteria are resistant to almost all of the third and fourth generation drugs [14]. There are several strains of Staphylococcus aureus that are even resistant to the fifth generation cephalosporins like ceftobiprole and ceftaroline. Therefore, novel strategies are being devised to generate future generation cephalosporins [14]. In addition to broad spectrum activities, 1,3-thiazine and its derivatives contains wonderful properties like antitumor, insecticide, and fungicidal. Further, these can be used as anti-radiation agents in radiationsickness [15]. The 4-hydroxy- N0-(benzylidene)-2H-benzo(e)(1,2) thiazine-3-carbohydrazide 1,1-dioxides [16] compounds possess not only antibacterial but also has radical scavenging activities and these properties are raised when more lipophilic is the compound [17]. Thus, such thiazine derivatives are useful chemical tools in biochemistry research and can be used in respiratory and photosynthetic electron transfer research where the free radicals are produced during normal activity as well as malfunction of some pathways. Patel., et al. made around forty different 1,2-benzothiazine derivatives, among which some only exhibited antibacterial activity against Gram positive bacteria [18].

\section{1, 3 thiazine}

Structure of 1, 3thiazines possesses an N-C-S linkage that is believed to be very useful units in the fields of medicinal and pharma- 
ceutical chemistry [10] 1,3thiazines and its derivatives have been reported to exhibit a variety of biological activities like Antibacterial, Antifungal, Antitubercular [19], Anti-inflammatory [20], Analgesic, Sedative-hypnotic, Immunosuppressive agents, etc. Some derivatives of thiazine are cannabinoid receptor agonists, also they can act as an anti-hypotensive. Moreover, thiazine derivatives can be used for gastrointestinal disorders or diabetes prevention. Condensed heterocyclic systems possessing thiazine ring have been reported as antioxidants, and calcium channel modulators 1 , 3-thiazines.are of great importance because they form part of the framework of cephalosporins (3, 6-dihydro-2H,1,3-thiazine) and also in some other medicinally important compounds like Xylazin (agonist at the $\alpha 2$ class of adrenergic receptor is used for sedation, anesthesia, muscle relaxation, and analgesia in animals), Chlormezanone (used as an anxiolytic and a muscle relaxant) etc. [9].

\section{Biological potential of 1 , 3-thiazines}

\section{Antimicrobial activity}

1,3-Thiazines and their derivatives have significant antimicrobial potential against various strains of bacteria, fungi etc. The core moiety of 1,3-thiazines (C-N-S) forms an active site in antibiotics like Cephalosporins. 1,3-Thiazines derived from chalcones viz. 4-(2-hydroxy-3,5-dichlorophenyl)-6- (ethyl)-2-iminophenyl-3phenyl-1,3-thiazine, 4-(2-hydroxy-3,5-dichlorophenyl)-6(ethyl)-2- iminophenyl-1,3-thiazine etc. have also been evaluated for their in vitro antimicrobial activity against various gram positive- Streptococcus aureus, S. subtilus and gram negative bacteria- E. coli and P. aeruginosa. Mamoru Koketsu., et al. 2002 synthesized series of 5,6- dihydro-4H-1,3-thiazine derivatives [22] which showed antimicrobial activity against M. tuberculosis H37Rv. Tarik EL-Sayed Ali., et al. 2010 synthesized 1,3-thiazine derivatives having acridine ring which besides showing antimicrobial activity against above mentioned species, also exhibit antibacterial activity against Streptococcus pyogenes and Pseudomonas fluorescens and Pseudomonas phaseolicola and antifungal activity against Fusarium oxysporum and Aspergillus fumigates. Ramesh L. Sawant., et al. 2011 introduced electron donating groups like hydroxyl and methoxy group at the fourth position of phenyl rings in the series of 6-[4-substitutephenyl]-4-phenyl-6H-1,3-thiazine2-amines and N-[6-(4- substitutedphenyl)-4-phenyl-6H-1,3-thiazine-yl] acetamides which enhances their antimicrobial activity. Farooque Haider Zulfequar Haider, 2012 synthesized series of 4-(2-hydroxy-5-substitutedphenyl)-5-benzoyl-6-substitutedphe-
nyl-2-imino-6H-2,3-dihydro-1,3-thiazine derivatives which exhibits antimicrobial activity due to the presence of phenolic group. Its antibacterial activity has been observed to be enhanced by increasing the number of heteroatoms in the heterocyclic system. Thanusu J., et al. 2010 introduced morpholine ring in the series of 4-(4-morpholinophenyl)-6-aryl-1,3- thiazin-2-amines which showed substiantial antibacterial activity against V.cholera etc. and antifungal activity against various strains of fungi viz. Rhizopus, $M$. gyseum [23] etc.

\section{Other activities of 1, 3 -thiazines}

Li Fu., et al. 2010 procured series of 6H-2-amino-4-aryl-6-(4$\beta$-D-allopyranosyloxyphenyl)-1,3-thiazines by Claisen Schmidst condensation which show strong calming activity in comparison with parent helicid.4 T.P.Trofimova., et al. 2008 gave a reaction scheme to synthesize 2-N-acylamino-5,6-dihydro-4H- 1,3-thiazines which showed excellent NOS inhibiting activity both in vivo and in vitro and also act as antihypotensive agents in vivo. $16 \mathrm{Kai} \mathrm{H}$., et al. 2008 synthesized 2-arylimino-5,6-dihydro-4H-1,3- thiazines which show profound analgesic properties [24]. Tetrahydro-1,3thiazines derivatives, tetrahydro [1,3]-thiazine-4-one-6-carboxylic acid, tetrahydro [1,3]-thiazin-4,6-dione derivatives, 2-(2-amino4-phenyl-6H-1,3-thiazin-6-yl)-4-[3-(2-amino-4-phenyl-6H-1,3thiazine-6-yl) 4-hydroxy-benzyl]phenol and 2-[2-amino-4-(4chlorophenyl)-6H-1,3-thiazin-6-yl]-4-hydroxybenzyl $\}$ phenol etc. have also been known to exhibit strong anti-inflammatory activity and most of them are immunotropic in nature [Zawisza T., et al. (1978\&1981); R. Kalirajan., et al. ( 2009), A. Nagaraj., et al. (2008)]. Derivatives of 1,2,4-triazolo [3, 2-b]-1,3-thiazine-7-ones and amino/ guanidine thiazine derivatives besides, possessing anti-inflammatory activity, also exhibits analgesic properties [Tozkoparan B., et al. (2002); Vijay V. Dabholkar., et al. (2011)] [25]. The derivatives of $1 \mathrm{H}$-pyrrolo [1, 2-c] [1,3] thiazine have been reported to show moderate anticonvulsant activity [Tadeusz S. Jagodzinski., et al. 2003] [26].

\section{Agrochemical uses of 1,3-thiazine derivatives}

Tetrahydro-2-(nitromethylene)-2H-1,3-thiazine (Nitromethylene) possess strong insecticidal properties (111) [Margulies, L., et al. (1988)] [27]. Perhydro dervivatives of 1,3-thiazine have obtained patent for their insecticidal properties against various nematodes [Jean-dominique bourzat., et al. (1981)] [28]. 
Thus, variously substituted 1, 3-thiazine derivatives procured largely through cyclo-condensations and few ring transformations have great synthetic utility, particularly for the synthesis of different heterocyclic systems. Besides having synthetic applications, these have also been remarkably known for their biological activities viz. pharmaceutical, agrochemical etc.

\section{Research envisaged}

Antibacterial agents are used for the treatment of bacterial diseases by interfering with the growth and reproduction of bacteria. Generally heat, chemicals and other antibiotic drugs having antibacterial properties were used for the treatment purpose in past.

Globally, antibacterial resistance has now a day seems very big challenge to the effective treatment of infections. Drug resistance adversely affects both sides: clinical as well as financial therapeutic outcomes. By seeing this scenario, new antibacterial agent having potent activity against the resistant microorganisms needed to be developed. Although many effective antibiotics are available now a day, but the change in nature of health cares and constant evolution of bacterial pathogens will create need and opportunities for significantly improved drugs.

Thus in order to overcome these problems there is a need to develop alternate therapeutic agents with selective antibacterial activity without risk of harmful side effects and resistance.

The thiazines possess a nitrogen and sulphur atoms in a six member ring that is believed to be important for their antifungal, anticonvulsant, and antiviral activities. The uniqueness and resourcefulness of the simple thiazine chemical structure and easy availability make thiazines and their derivatives amongst the most gifted sources of bioactive compounds.

Literature survey shows, nucleus has diverse antibacterial activity. Therefore, keeping the above consideration it was thought worthwhile to design a new series of thiazine derivatives with different substituents, on position 2,3and 4 of phenyl ring attached at 6 position of thiazine ring with different substituted benzaldehyde derivatives as electron-withdrawing group, and evaluate them for antibacterial activity.

Plan of work

- $\quad$ Literature survey.<smiles>[R]c1ccc([C@H]2C=C(c3cc(Cl)cc([N+](=O)[O-])c3O)NC(=N)S2)cc1</smiles>

A<smiles>[R]c1ccc([C@H]2C=C(c3cc(Cl)cc([N+](=O)[O-])c3O)NC(=N)S2)cc1</smiles>

B

Figure c: General Structure.
- Selection of compounds for synthesis.

- Optimization of reaction conditions.

- Synthesis of designed compounds.

- Determination of physicochemical properties-

- Solubility.

- Melting Point determination.

- $\mathrm{R}_{\mathrm{f}}$ value determination.

- Partition coefficient (Log P determination).

- Microbiological evaluation of synthesized compounds-

- Minimum Inhibitory Concentration.

\section{Materials and Methods}

Computational studies

Computational studies were used to designed the series of 1 , 3- Thiazine derivatives.

Docking

Docking is a computerized method through which we can be determines the binding efficiency of a compound with the active 
site of the proteins. This method determines the orientation of the compounds, conformational geometry of the compound and scoring.

Steps involved in docking

Proteins download

The "PDB ID-1Q1Y"is the PDB ID for Staphylococcus aureus, and "PDB ID-4AMV"is the PDB ID for Escherichia coli. These protein fi-

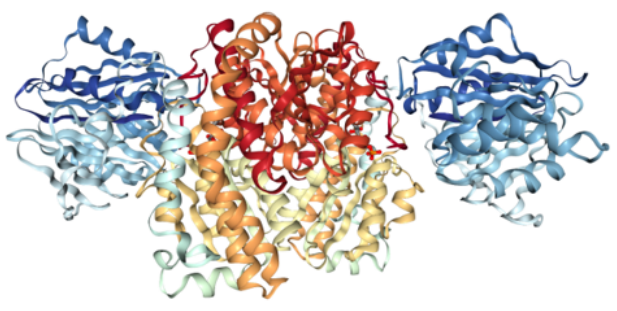

Figure 1: Structure of 4AMV (PDB ID).

\section{Ligand preparation}

The structure of ligands was drawn by using ChemDraw Ultra 8.0 and energy was minimized in chem Draw 3D Ultra 8.0 and saved in mole2 format.

\section{Defining binding site}

The binding site of protein was defined by selecting all atoms within $10 \AA$, which was found by redocking the native ligand at the active site. les were downloaded from RCSB (research Collaboratory for structure bioinformatics) protein data bank, and saved in PDB format.

\section{Protein preparation}

Proteins were prepared in UCSF Chimera 1.7S Software by, selecting in suitable chain. Water molecules were removed, and the protein was saved in PDB format.

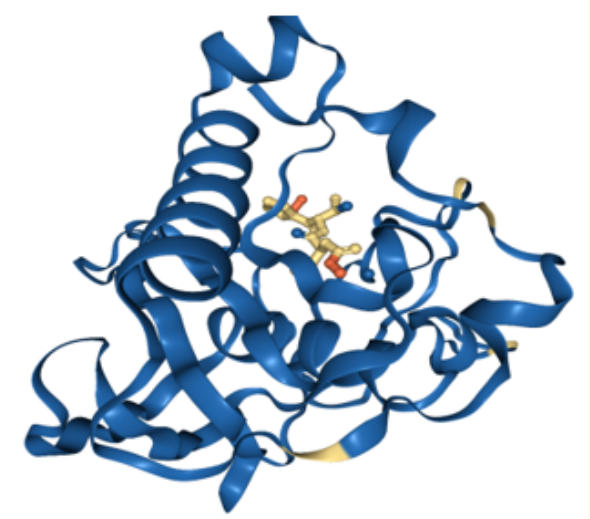

Figure 2: Structure of 1Q1Y (PDB ID).

\section{Docking in molegro virtual docker}

Docking is an essential tool for fast consideration of the binding efficiency of ligand with its target protein i.e. enzyme. Docking is a commercial and timesaving method for the invention of lead compounds. In current years, the virtual screening for docking of small molecules with a known protein structure has become a powerful

\begin{tabular}{|l|c|}
\hline \multicolumn{1}{|c|}{ Compound code } & IUPAC Name \\
\hline Ptt2m & $\begin{array}{c}\text { S,Z)-4-chloro-2-nitro-6-(2-(phenylimino)-6-(o-tolyl)- } \\
\text { 3,6-dihydro-2H-1,3-thiazin-4-yl)phenol }\end{array}$ \\
\hline
\end{tabular}




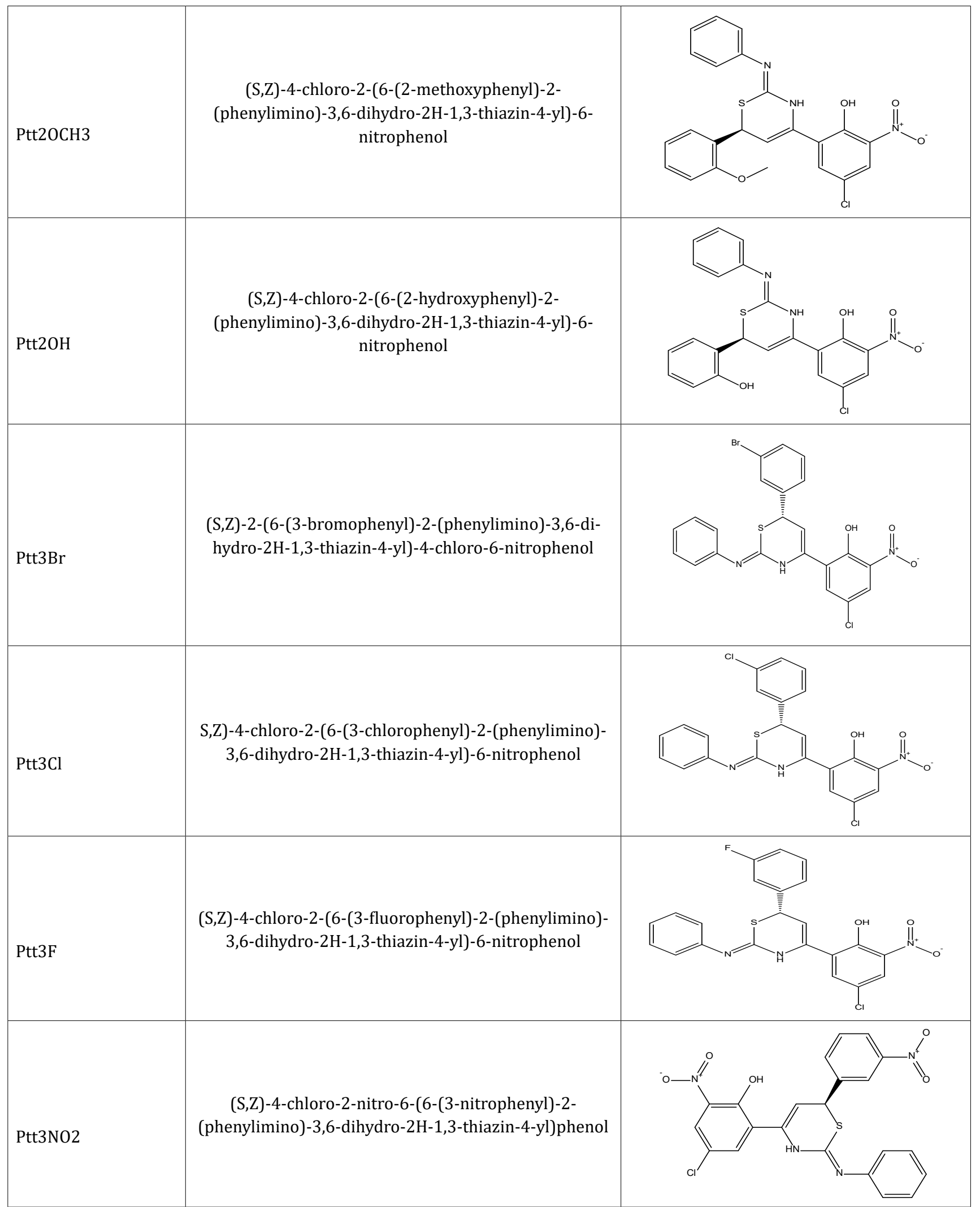

Citation: Khan Sana., et al. "Design, Synthesis and Antimicrobial Activities Evaluation of 1, 3 Thiazine Derivatives". Acta Scientific Pharmaceutical Sciences 5.7 (2021): 141-158. 


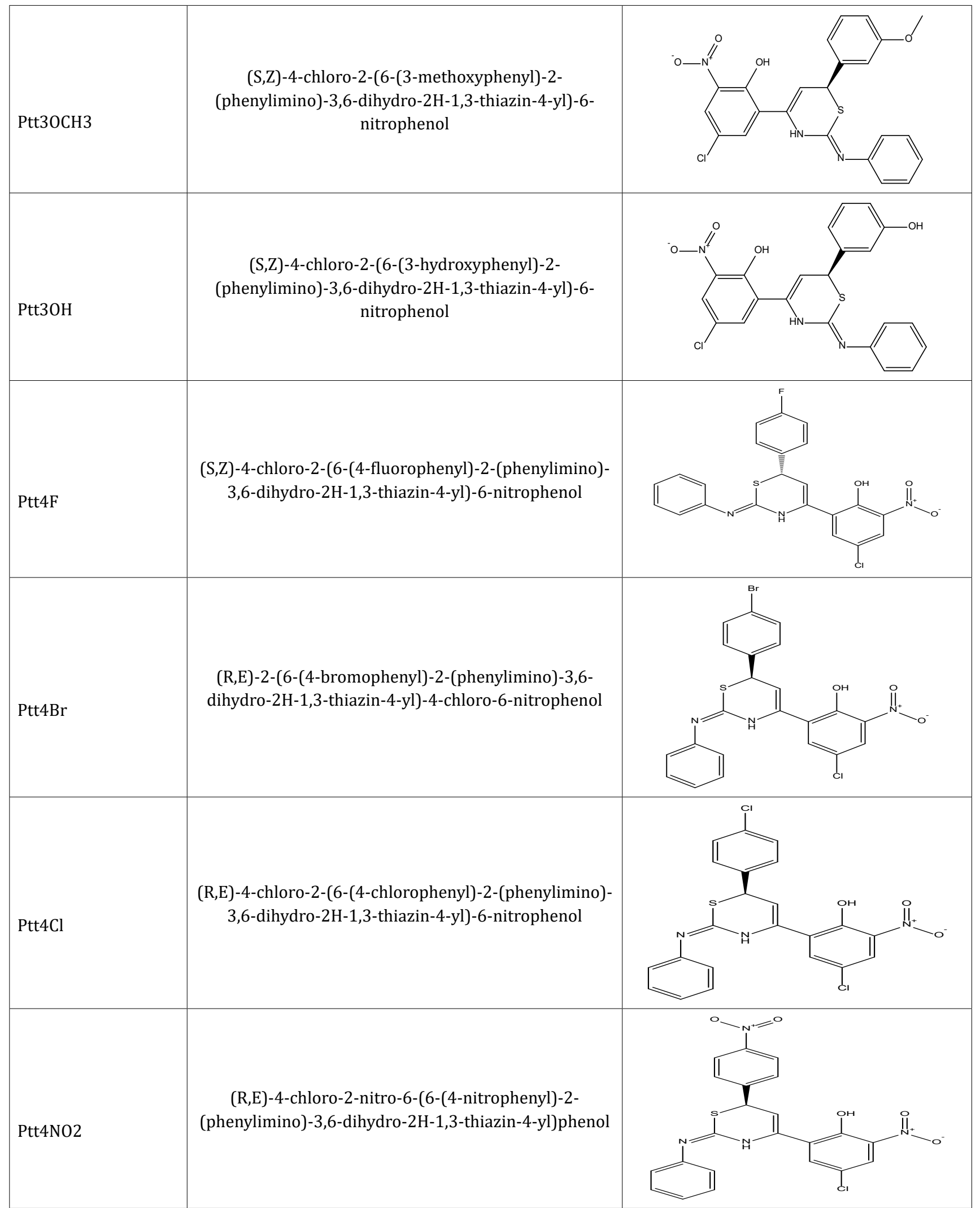




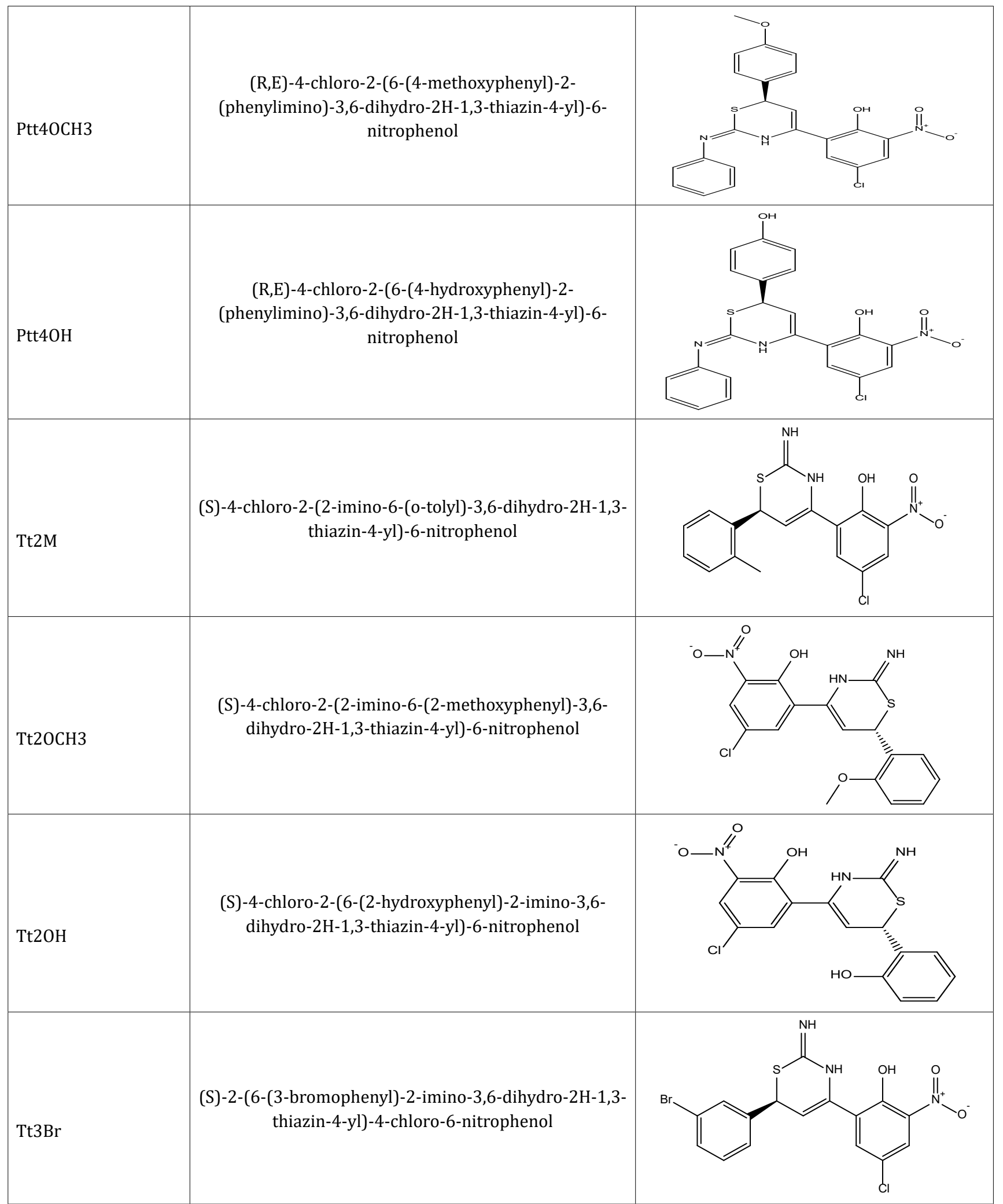

Citation: Khan Sana., et al. "Design, Synthesis and Antimicrobial Activities Evaluation of 1, 3 Thiazine Derivatives". Acta Scientific Pharmaceutical Sciences 5.7 (2021): 141-158. 


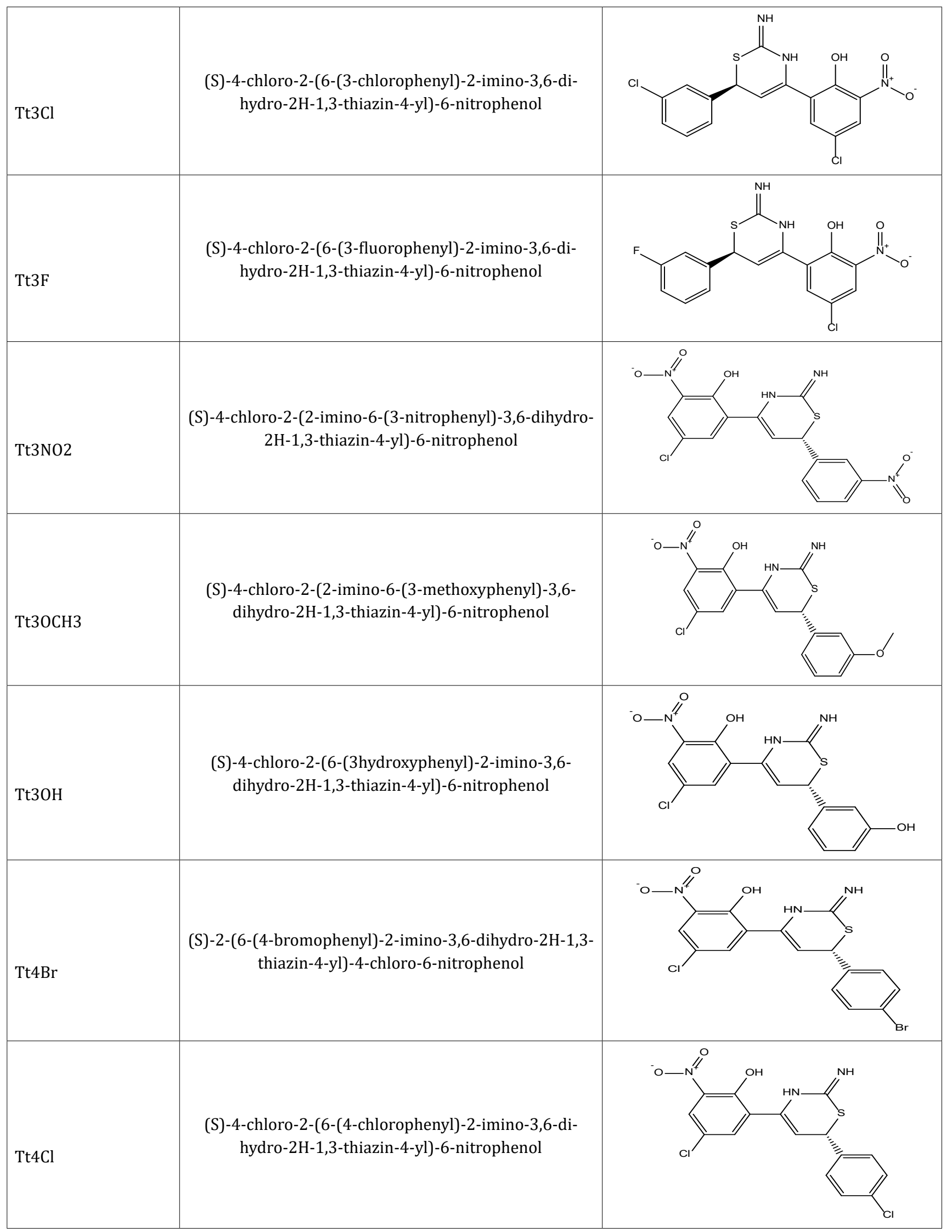




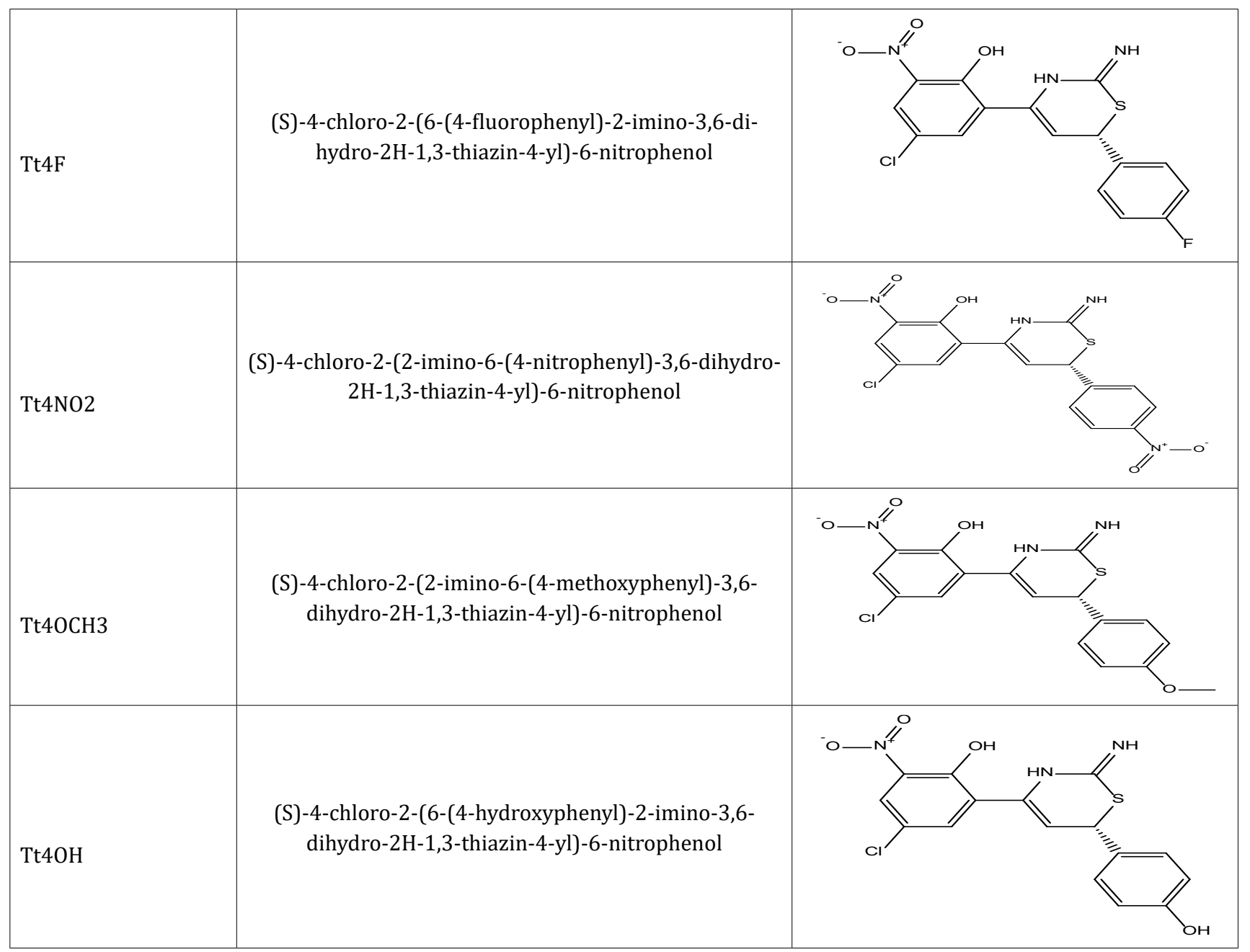

Table 1: Structure of ligand prepared with compound code ande IUPAC name.

tool for drug design and also become an essential part of the drug discovery. Molegro Virtual Docker is non-commercial docking software. Molegro Virtual Docker 6.0 developed by CLC drug discovery Workbench.

Docking Score of compounds by using Molegro Virtual Docker 6.0 software

\section{Analysis of docking score}

- 4AMV: The entire 30 1, 3 Thiazine derivatives bind with 4AMV protein (Glucosamine fructose 6-p- aminotransferase) and interaction was observed. Ptt4Cl showed the highest MolDock Score -110.723 as compared with reference drug Ampicillin.

\begin{tabular}{|l|c|c|c|}
\hline $\begin{array}{c}\text { Compound } \\
\text { Code }\end{array}$ & MolDock Score & Rerank Score & HBond \\
\hline $\mathrm{Ptt} 4 \mathrm{Cl}$ & -110.723 & -78.4613 & -5.48575 \\
\hline $\mathrm{Tt} 4 \mathrm{OH}$ & -106.654 & -81.0678 & -12.0967 \\
\hline $\mathrm{Tt} 20 \mathrm{CH} 3$ & -105.444 & -82.119 & -9.53857 \\
\hline $\mathrm{Tt} 4 \mathrm{~F}$ & -101.536 & -84.3331 & -8.70252 \\
\hline $\mathrm{Ptt3OCH3}$ & -101.001 & -73.0568 & 0 \\
\hline $\mathrm{Tt} 3 \mathrm{NO2}$ & -100.075 & -83.0619 & -6.9303 \\
\hline $\mathrm{Tt} 30 \mathrm{CH} 3$ & -99.7293 & -81.9545 & -5.54038 \\
\hline $\mathrm{Ptt} 30 \mathrm{H}$ & -97.2969 & -70.4167 & -4.49777 \\
\hline $\mathrm{Ptt} 4 \mathrm{~F}$ & -96.3454 & -53.6497 & -4.13648 \\
\hline
\end{tabular}




\begin{tabular}{|l|c|c|c|}
\hline Tt3OH & -95.1179 & -71.0299 & -9.45847 \\
\hline Tt4OCH3 & -93.706 & -76.7804 & -3.95941 \\
\hline Ptt4F & -93.3741 & -74.005 & -5.86158 \\
\hline Ptt2OCH3 & -92.5215 & -65.9773 & 0 \\
\hline Tt2M & -91.3958 & -75.2571 & -3.2033 \\
\hline Tt2OH & -89.3392 & -77.6952 & -8.23625 \\
\hline TT3F & -89.1138 & -74.7265 & -5.3147 \\
\hline TT4Br & -88.8064 & -74.5592 & -6.18152 \\
\hline Ptt4NO2 & -88.6181 & 10.7845 & -6.41836 \\
\hline Tt3Br & -88.4113 & -64.5513 & -6.57065 \\
\hline Tt3Cl & -87.8743 & -73.2045 & -8.15926 \\
\hline Tt4NO2 & -86.8956 & -58.2635 & -9.75651 \\
\hline Tt4Cl & -86.7749 & -67.5634 & -6.83585 \\
\hline Ptt4OCH3 & -86.7144 & 19.3956 & -6.50447 \\
\hline Ptt2M & -86.1307 & -26.7007 & -6.73811 \\
\hline Ptt3Br & -85.2379 & 25.2003 & -8.73745 \\
\hline Ptt4Br & -82.4321 & 19.6867 & -6.4191 \\
\hline Ptt4OH & -81.9273 & 19.5981 & -6.47967 \\
\hline Ptt3NO2 & -79.8643 & 72.2411 & -6.64596 \\
\hline Ptt2OH & -73.8775 & -16.0809 & 0.881268 \\
\hline Ptt3F & -72.9588 & -3.93201 & -8.5393 \\
\hline Ptt3Cl & -69.3499 & 40.2221 & -6.63596 \\
\hline
\end{tabular}

\begin{tabular}{|l|c|c|c|}
\hline Ptt2M & -90.7249 & -72.7707 & -1.29751 \\
\hline Ptt2OH & -90.2557 & -71.9369 & -4.85802 \\
\hline Tt3NO2 & -90.2013 & -73.9158 & -4.97568 \\
\hline Ptt4F & -89.904 & 1.32502 & -2.10633 \\
\hline Ptt3Br & -89.4501 & -72.4944 & -1.22774 \\
\hline Tt4OCH3 & -87.6422 & -70.5666 & -6.48139 \\
\hline Ptt4Cl & -87.4778 & -66.6463 & -7.1557 \\
\hline Tt2OCH3 & -87.0455 & -72.6424 & -4.83831 \\
\hline Tt3OH & -86.8145 & -70.3878 & -10.5391 \\
\hline Tt4NO2 & -85.0538 & -69.3519 & -4.87202 \\
\hline Tt4Br & -84.5862 & -66.6038 & -4.37323 \\
\hline Tt4F & -84.0047 & -66.2733 & -5.01028 \\
\hline Tt4Cl & -83.9601 & -66.2623 & -4.97171 \\
\hline Tt3F & -83.8048 & -67.6772 & -4.613 \\
\hline Tt2M & -83.3401 & -68.0274 & -4.71991 \\
\hline Tt4OH & -83.252 & -66.2025 & -3.71184 \\
\hline Tt3Cl & -83.022 & -66.7699 & -4.46023 \\
\hline Tt3Br & -82.6209 & -66.2686 & -4.67272 \\
\hline Tt2OH & -81.2521 & -66.3319 & -6.93566 \\
\hline
\end{tabular}

Table 3: Docking score of compounds for S. aureus (1Q1Y).

Table 2: Docking score of compounds for E. coli (4AMV).

\begin{tabular}{|l|c|c|c|}
\hline Compound Code & $\begin{array}{c}\text { MolDock } \\
\text { Score }\end{array}$ & $\begin{array}{c}\text { Rerank } \\
\text { Score }\end{array}$ & HBond \\
\hline Ptt3OCH3 & -96.683 & -77.2286 & -1.35372 \\
\hline Ptt3NO2 & -96.5314 & -79.9126 & -1.58689 \\
\hline Ptt4NO2 & -96.5073 & -80.1216 & -4.02885 \\
\hline Ptt4OCH3 & -95.4961 & -77.3788 & -3.69138 \\
\hline Ptt4OH & -94.7954 & -78.3154 & -5.3336 \\
\hline Ptt3OH & -94.431 & -72.8265 & -5.96018 \\
\hline Ptt3F & -92.701 & -73.9804 & -1.32963 \\
\hline Ptt3Cl & -92.1713 & -73.5393 & -1.41149 \\
\hline Ptt4Br & -92.1642 & -75.5591 & -4.89751 \\
\hline Ptt2OCH3 & -91.4593 & -67.6821 & -3.02657 \\
\hline Tt30CH3 & -91.0537 & -75.6174 & -8.00002 \\
\hline
\end{tabular}

- 1Q1Y: The entire 30 1, 3 Thiazine derivatives bind with 1Q1Y protein (crystal structure of peptide deformylase) and interaction was observed. Ptt3OCH3 showed the highest MolDock Score -96.683 as compared with reference drug Ampicillin.

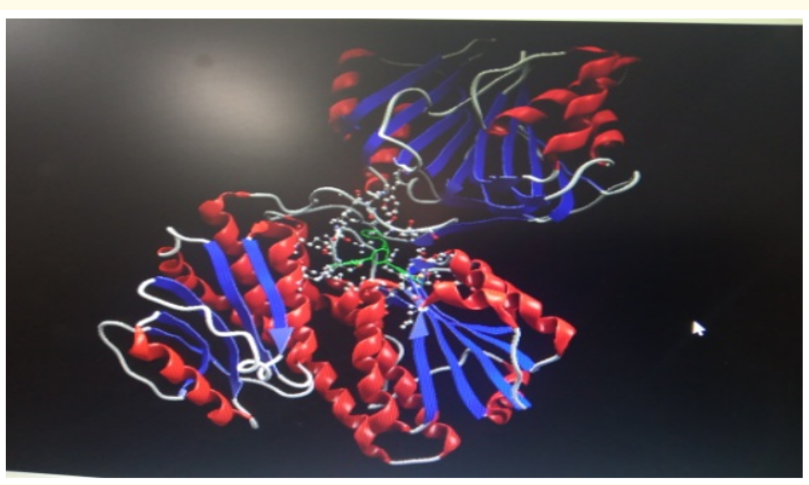

Figure 3: Docking complex of 4AMV 5a.

Citation: Khan Sana., et al. "Design, Synthesis and Antimicrobial Activities Evaluation of 1, 3 Thiazine Derivatives". Acta Scientific Pharmaceutical Sciences 5.7 (2021): 141-158. 


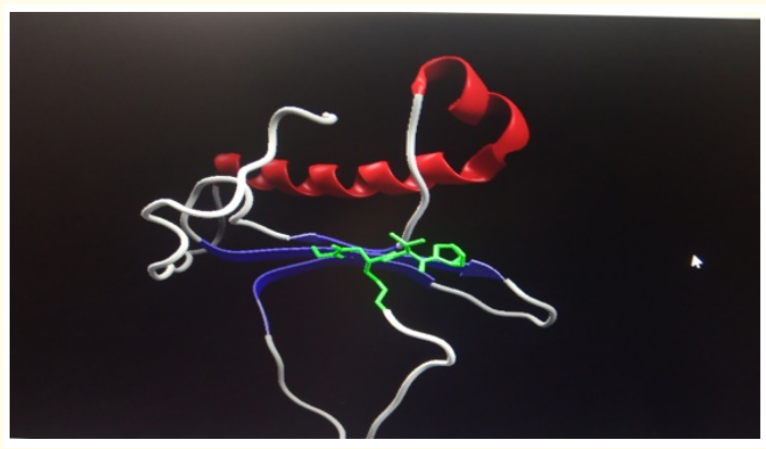

Figure 4: Docking complex of $1 \mathrm{Q} 1 \mathrm{Y}$ with $5 \mathrm{~d}$.

Scheme: Synthesis of 1, 3-thiazine derivatives

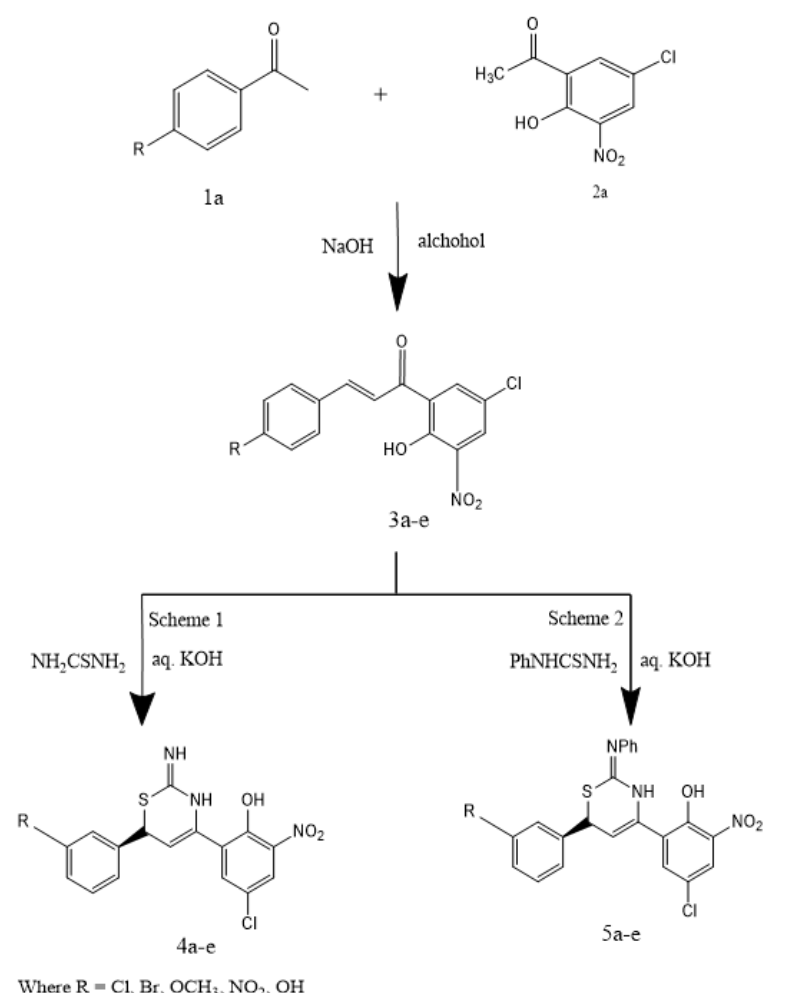

Figure d
Synthesis of 1, 3-thiazine derivatives

Steps for the synthesis of designed compounds

Preparation of 2-hydroxy-3-nitro-5-chloroacetophenone (2a)

2-Hydroxy-5-chloroacetophenone (3g) was dissolved in glacial acetic acid (3ml). Nitric acid was added to the mixture. The temperature was maintained below $0^{\circ} \mathrm{C}$.Then stand for 1 hour. Then poured it into ice cold water and stirred it continuously. Then filtered, dried and crystallized from ethanol.

Preparation of 2-hydroxy-3-nitro- 5-chlorochalcones (3a-e)

2-Hydroxy-3-nitro-5-chloroacetophenone 2a (0.1M) was dissolved in ethanol $(50 \mathrm{ml})$ and then derivatives of benzaldehyde $(0.1 \mathrm{M})$ were added to the reaction mixture and then heated up to boiling. Then drop wise $\mathrm{NaOH}$ (40\%, $40 \mathrm{ml}$ ) was added and stirred it properly. Then reaction mixture was stirred mechanically for half an hour at room temperature and kept it for overnight. After that acidified it by $\mathrm{HCl}$ solution. Filtered the mixture and washed with $\mathrm{Na}_{2} \mathrm{CO}_{3}$ and water. The product was crystallized from ethanol and acetic acid mixture.

Preparation of 4-(2-hydroxy-3-nitro-5-chlorophenyl) -6 (4-chlorophenyl) -2-imino -3, 6 dihydro-1, 3-thiazines (4a-e)

2-Hydroxy-3-nitro-5-chlorochalcone 3a-e and thiourea (0.01M) were dissolved in ethanol $(25 \mathrm{ml})$ and $\mathrm{KOH}$ solution $(0.02 \mathrm{M})$ was added. Then mixture was refluxed for 2.5 hours diluted it with water and acidified with $\mathrm{HCl}$. The product was filtered, and crystallized (4a-e).

Preparation of 4-(2-hydroxy-3-nitro-5-chlorophenyl) -6- (benzyle) -2-iminophenyl - 3, 6 dihydro-1, 3-thiazine (5a-e)

2-hydroxy-3-nitro-5-chlorochalcone 4a-e, (0.01M) was dissolved in ethanol $(25 \mathrm{ml})$ and added to phenylthiourea $(0.01 \mathrm{M})$ then aq. $\mathrm{KOH}(0.02 \mathrm{M})$ was added. Then mixture was refluxed for 2.5 hours diluted it with water and acidified with $\mathrm{HCl}$. The product was filtered, dried and crystallized (5a-e).

The synthesized compounds (4a, 4b, 4c, 4d, 4e, 5a, 5b, 5c, 5d, 5 e) were characterized on the basis of physicochemical properties and spectroscopy studies.

\section{Determination of physicochemical properties}

The various physicochemical properties of the synthesized compounds were determined: 
- $\quad$ Melting point

- $R_{f}$ value

- Solubility

- Partition Coefficient.

\section{Melting point}

The melting point of synthesized compounds was determined by open capillary method. Melting Points are reported in table.

\section{Rf value}

$\mathrm{R}_{\mathrm{f}}$ value of synthesized compounds and their intermediate were determined by thin layer chromatography (TLC) using silica gel 60 F 254. Hexane: Ethyl acetate (9:1) was used as a solvent system. The spots were applied on a silica gel plate and the plate was run in a closed chamber. The spots on the plate were detected in iodine chamber and $\mathrm{R}_{\mathrm{f}}$ value are reported in table.

\section{Solubility}

The Solubility was determined in various solvents and all compounds were soluble in Ethanol, water, ethanol, chloroform, benzene, and hexane qualitatively.

\section{Partition coefficient}

Partition Coefficient of synthesized compounds was determined by using octanol: water in equal ratio and Log $\mathrm{P}$ of compounds are reported in table.

\begin{tabular}{|c|c|c|c|c|c|}
\hline $\begin{array}{c}\text { Compound } \\
\text { Code }\end{array}$ & $\mathbf{R}$ & $\begin{array}{c}\text { Partition } \\
\text { Coefficient } \\
\text { (Log P) }\end{array}$ & M.P $\left({ }^{0} \mathrm{C}\right)$ & $\begin{array}{c}\% \\
\text { yield }\end{array}$ & Rf value \\
\hline $\mathrm{Tt} 3 \mathrm{Cl}$ & $\mathrm{Cl}$ & 0.311 & $120-122$ & 76 & 0.55 \\
\hline $\mathrm{Tt} 3 \mathrm{Br}$ & $\mathrm{Br}$ & 0.170 & $145-147$ & 68 & 0.58 \\
\hline $\mathrm{Tt} 3 \mathrm{OCH}_{3}$ & $\mathrm{OCH}_{3}$ & 0.314 & $102-106$ & 58 & 0.68 \\
\hline $\mathrm{Tt} 3 \mathrm{NO}_{2}$ & $\mathrm{NO}_{2}$ & 0.277 & $138-140$ & 70 & 0.64 \\
\hline $\mathrm{Tt} 30 \mathrm{H}$ & $\mathrm{OH}$ & 0.120 & $132-135$ & 51 & 0.72 \\
\hline $\mathrm{Ptt} 3 \mathrm{Cl}$ & $\mathrm{Cl}$ & 0.130 & $110-112$ & 74 & 0.69 \\
\hline Ptt3Br & $\mathrm{Br}$ & 0.243 & $157-160$ & 75 & 0.49 \\
\hline $\mathrm{Ptt}_{3} \mathrm{OCH}_{3}$ & $\mathrm{OCH}_{3}$ & 0.440 & $142-145$ & 54 & 0.51 \\
\hline $\mathrm{Ptt}_{3} \mathrm{NO}_{2}$ & $\mathrm{NO}_{2}$ & 0.510 & $138-140$ & 60 & 0.35 \\
\hline $\mathrm{Ptt} 30 \mathrm{H}$ & $\mathrm{OH}$ & 0.590 & $140-142$ & 65 & 0.55 \\
\hline
\end{tabular}

Table 4: Physicochemical properties of synthesized compounds:

\section{Microbiological assay}

Microbiological assay is a comparison of the inhibition of growth of microorganisms between the measured concentrations of the test compounds which is produced by known concentrations of a standard preparation of the antibiotic having a known activity. There are various methods which are used to determine the effectiveness of antimicrobials. There are various method of microbiological assay which are as follow.

- Diffusion method

- Paper disc diffusion method

- Cylinder or Cup-plate method

- Agar plate method

- Turbidity method

- Agar streak dilution method

- Serial dilution method.

The anti-bacterial activities of synthesized compounds were determine against one gram- positive bacteria ( $S$. aureus) and one gram- negative bacteria (E. coli) by Agar disk diffusion method and the zone of inhibition was determined. In this test, wafers containing antibiotics was placed on an agar plate and bacteria were also placed on it and incubate it. The antibiotics stop the growth of the bacteria or kill the bacteria and the zone of inhibition was visible. Then zone of inhibition was measured.

Microbiological evaluation of synthesized compounds By Agar plate method

Standardization - Inoculation is made with a broth culture diluted to match a 0.5 McFarland turbidity standard, which is roughly equivalent to 150 million cells per ml.

Preparation of media: The media used in this method must be Mueller-Hinton agar at only $4 \mathrm{~mm}$ deep, poured into either $100 \mathrm{~mm}$ or $150 \mathrm{~mm}$ Petri dishes. The $\mathrm{pH}$ level of the agar must be between 7.2 and 7.4 .

Incubation procedure

- A sterile swab was placed into the broth culture of organism and the excess liquid was removed and by using swab, the Muller- Hinton agar plate was streak to form a bacterial lawn. 


\begin{tabular}{|l|c|c|}
\hline S. N. & Ingredients & Nutrient broth \\
\hline 1. & Beef Extract & $2.0 \mathrm{gm}$ \\
\hline 2. & Casein hydolysate & $17.5 \mathrm{gm}$ \\
\hline 3. & Starch & $1.5 \mathrm{gm}$ \\
\hline 4. & Agar & $17.0 \mathrm{gm}$ \\
\hline 5. & Distilled Water & Up to $1000 \mathrm{ml}$ \\
\hline
\end{tabular}

Table 5: Composition of Mueller-Hinton agar.

pH of medium adjusted to neutral at room temperature.

Reference standard: Azethromycine $(15 \mu \mathrm{g} / \mathrm{disc})$.

- $\quad$ Then the plate was allowed to dry for $5 \mathrm{~min}$. Use an antibiotic disc dispenser to dispense discs containing specific antibiotics on to the plate and the plate was incubated overnight at $37^{\circ} \mathrm{C}$.

Reading and interpreting results

The zone of inhibition was measured by first placed the plate on a white surface. Then with the help of ruler the zone of inhibition was measured from edge to edge crossing through the center and measure the diameter in $\mathrm{mm}$.

\section{Results and Discussion}

The experimental work involved Docking studies, ADMET prediction, analysis of designed compound, elemental analysis, bioactivity score prediction, synthesis, characterization, and antimicrobial evaluationIn the present work totally 10 compounds were synthesized in two scheme. Step 1 involves the formation of chalcones from 2-Hydroxy-3-nitro-5-chloroacetophenone. The step 1 product (chalcone) reacted with thiourea or phenyl thiourea in presence of potassium hydroxide undergo cyclization to form 1, 3-thiazine derivatives. Molecular docking studies were carried out for the synthesized compounds against E. coli Glucosamine -6 P Synthase in Complex with Fructose -6 P (PDB ID- 4 AMV) and Crystal structure of Peptide deformylase from Staphylococcus $\mathrm{Au}$ reus Complex with Actinonin (PDB ID- 1Q1Y) by using Molegro Virtual Docker software which gives an insight in to the binding modes for the various inhibitors. Out of 10 inhibitors analyzed 5a has showed Mol Dock Score of -110.723 for E. coli and $5 d$ has showed Mol Dock Score of -96.683 for S. aureus. The characterization of all ten synthesized compound were performed and structures were confirmed by ${ }^{1}$ HNMR and Mass spectroscopy. Then all ten derivatives of 1, 3-thiazine were screened for their antimicrobial activ- ity against gram positive bacteria viz. S. aureus and gram negative bacteria viz. E. coli species at conc. of $1000 \mu \mathrm{m}$ azethromycine as a standard using agar plate techniques. The zone of inhibition formed were measured in $\mathrm{mm}$ and shown in table.

Docking score of synthesized compounds

\begin{tabular}{|l|c|c|c|}
\hline Compound code & $\begin{array}{c}\text { MolDock } \\
\text { Score }\end{array}$ & $\begin{array}{c}\text { Rerank } \\
\text { Score }\end{array}$ & HBond \\
\hline $\mathrm{Tt} 4 \mathrm{Cl}$ & -86.7749 & -67.5634 & -6.83585 \\
\hline $\mathrm{Tt} 4 \mathrm{Br}$ & -88.8064 & -74.5592 & -6.18152 \\
\hline $\mathrm{Tt4OCH} 3$ & -93.706 & -76.7804 & -3.95941 \\
\hline $\mathrm{Tt4NO2}$ & -86.8956 & -58.2635 & -9.75651 \\
\hline $\mathrm{Tt4OH}$ & -106.654 & -81.0678 & -12.0967 \\
\hline $\mathrm{Ptt} 4 \mathrm{Cl}$ & -110.723 & -78.4613 & -5.48575 \\
\hline $\mathrm{Ptt} 4 \mathrm{Br}$ & -82.4321 & 19.6867 & -6.4191 \\
\hline $\mathrm{Ptt} 40 \mathrm{OH} 3$ & -86.7144 & 19.3956 & -6.50447 \\
\hline $\mathrm{Ptt} 4 \mathrm{NO2}$ & -88.6181 & 10.7845 & -6.41836 \\
\hline $\mathrm{Ptt} 40 \mathrm{H}$ & -81.9273 & 19.5981 & -6.47967 \\
\hline
\end{tabular}

Table 6: Summary of docking score of synthesized 1,3-thiazine derivatives against target $E$. coli Glucosamine- 6 PSynthase in Complex with Fructose -6 P.

\begin{tabular}{|l|c|c|c|}
\hline \multicolumn{1}{|c|}{$\begin{array}{c}\text { Compound } \\
\text { code }\end{array}$} & $\begin{array}{c}\text { Mol Dock } \\
\text { Score }\end{array}$ & $\begin{array}{c}\text { Rerank } \\
\text { Score }\end{array}$ & HBond \\
\hline $\mathrm{Tt} 4 \mathrm{Cl}$ & -83.9601 & -66.2623 & -4.97171 \\
\hline $\mathrm{Tt} 4 \mathrm{Br}$ & -84.5862 & -66.6038 & -4.37323 \\
\hline $\mathrm{Tt} 4 \mathrm{OCH} 3$ & -87.6422 & -70.5666 & -6.48139 \\
\hline $\mathrm{Tt} 4 \mathrm{NO} 2$ & -85.0538 & -69.3519 & -4.87202 \\
\hline $\mathrm{Tt} 4 \mathrm{OH}$ & -83.252 & -66.2025 & -3.71184 \\
\hline $\mathrm{Ptt} 4 \mathrm{Cl}$ & -87.4778 & -66.6463 & -7.1557 \\
\hline $\mathrm{Ptt} 4 \mathrm{Br}$ & -92.1642 & -75.5591 & -4.89751 \\
\hline Ptt4OCH3 & -95.4961 & -77.3788 & -3.69138 \\
\hline Ptt4NO2 & -96.5073 & -80.1216 & -4.02885 \\
\hline Ptt4OH & -94.7954 & -78.3154 & -5.3336 \\
\hline
\end{tabular}

Table 7: Summery of docking score of all synthesized 1, 3-thiazine derivatives against the target Crystal structure of Peptide deformylase from Staphylococcus Aureus Complex with Actinonin.

Microbiological evaluation of synthesized compounds

The antimicrobial evaluation of 1, 3 -thiazine derivatives conclude that the synthesized compounds were shown the potent 
antimicrobial activity against $E$. coli and $S$. aureus respectively as compared to Azithromycin as a reference. And it also be concluded that 1,3-thiazine derivatives posses more antimicrobial activity on gram negative (E. coli) bacteria than gram positive bacteria ( $S$. aureus).

\begin{tabular}{|l|c|c|}
\hline \multirow{2}{*}{$\begin{array}{c}\text { Compound } \\
\text { Code }\end{array}$} & \multicolumn{2}{|c|}{ Zone of inhibition(mm) } \\
\cline { 2 - 3 } & E. coli & S. aureus \\
\hline $\mathrm{Tt} 4 \mathrm{Cl}$ & 17 & 16 \\
\hline $\mathrm{Tt} 4 \mathrm{Br}$ & 20 & 17 \\
\hline $\mathrm{Tt} 40 \mathrm{OH} 3$ & 23 & 19 \\
\hline $\mathrm{Tt} 4 \mathrm{NO2}$ & 19 & 17 \\
\hline $\mathrm{Tt} 4 \mathrm{OH}$ & 25 & 15 \\
\hline $\mathrm{Ptt} 4 \mathrm{Cl}$ & 26 & 19 \\
\hline Ptt4Br & 17 & 18 \\
\hline Ptt4OCH3 & 19 & 19 \\
\hline Ptt4NO2 & 20 & 21 \\
\hline Ptt4OH & 17 & 21 \\
\hline
\end{tabular}

Table 8: Antimicrobial activities of all synthesized 1, 3- thiazine derivatives.

The synthesized compounds were shown the potent antimicrobial activity against $E$. coli and $S$. aureus respectively as compared to Azithromycin (standard reading $\geq 18 \mathrm{~mm}$ ) as a reference.

\section{Conclusion}

From last decades, the rise in drug resistant bacterial infection has become a very serious health care problem. Drug-resistance is generally acquired by the genetic mutation, this process takes long time but once the resistance is acquired, it spreads throughout the species. The infections once easy to treat are becoming difficult due to resistance development, and it became major problem for the researchers to design the molecules which can overcome resistance. Therefore, there is a need for the development of new agents which have better activity.

Thiazine derivatives are important and useful drugs. The thiazine derivatives are known to possess antibacterial, antifungal, antiviral, activities. Some benzimidazole containing marketed drugs are thiabendazole, norastemizole, telmisartan, omeprazole etc. The literature show that the thiazine derivatives substituted at position 2 ,3and 4 of phenyl ring attached at 6 position of thiazine ring show significant activity against bacteria, fungi etc. which encouraged the design and synthesis of some new substituted thiazine derivatives active against bacteria.

The 4-hydroxy-phenyl thiourea thiazine and 3-methoxy-phenyl thiourea thiazine derivatives were synthesized and purified by recrystallization. The layer chromatography was used for monitoring the reaction. Hexane: Ethyl (9:1) was used as a solvent system and spot were observed in Iodine chamber. Melting point was determined by open capillary method. The characterization was performed and structure of all compounds was confirmed by ${ }^{1} \mathrm{H}$ NMR and mass spectroscopy. The ${ }^{1}$ HNMR spectra were recorded using DMSO-d6 as the solvent and TMS as internal standard. The Mass spectroscopy was recorded by using Bruker, micro-TOF-Q II 10348 and ESI-MS technique for ionization of samples.

The anti-microbial activity of product was evaluated against two different strains of micro-organisms; one gram-positive bacteria (S. aureus), and one gram-negative bacteria (E. coli). The antimicrobial evaluation was performed by agar plate method and zone of inhibition was measured in $\mathrm{mm}$.

The result of microbiological evaluation revealed that ten different 1, 3 Thiazine derivatives were synthesized from chalcones and thiourea or phenyl thiourea. The products were checked for their anti-microbial activity by molecular docking studies against E. coli and Staphylococcus Aureus by using Molegro Virtual Docker software. Then in-vitro evaluation of anti-microbial activity of all compound of 1, 3 Thiazine derivatives were performed and all having considerable anti-microbial activity. From the above results it would be concluded that 1, 3-thiazines derivatives possess more anti-microbial activities on gram-negative E. coli bacteria than gram-positive bacteria $S$. aureus. The parent nucleus further could be explored to obtain more potent derivatives.

\section{Acknowledgment}

I would like to express my sincere thanks to Saiyed Tosheb Ali.

\section{Bibliography}

1. Abraham DJ., et al. "Computer aided drug design Method and application”. New York 1.26 (1988): 93.

2. Deepika G., et al. "Synthesis and antibacterial activity of some new thiazine derivatives". Journal of Pharmaceutical Sciences 5 (2012): 1105-1107. 
3. Chaviara AT., et al. "Copper (II) Schiff base coordination compounds of dien with heterocyclic aldehydes and 2-amino5-methyl-thiazole: Synthesis, characterization, antiproliferative and antibacterial". Journal of Inorganic Biochemistry 98.8 (2004): 1271-1283.

4. Joshi H., et al. "Studies on 4-thiazolidinones: Synthesis and antimicrobial activity of 1, 4-bis (20-aryl-50 (H)-40-thiazolidinone-30 ylamino)phthalazine". Journal of the Indian Chemical Society 67 (1990): 779-780.

5. Cheng G., et al. "Antimicrobial drugs in fighting against antimicrobial resistance". Frontiers in Microbiology 7 (2016): 470.

6. Ebimieowei E and Ibemologi A. "Antibiotice classification and mechanism of action with emphasis on molecular perspectives". IJAMBR 4 (2016): 90-101.

7. Pelczar MJ., et al. "Antimicrobials in Laboratory Medicine". Microbiology 5th edition, New Delhi, (2003): 85.

8. Jackson N., et al. "Discovery and development of new antibacterial drugs: learning from experience". Journal of Antimicrobial Chemotherapy 73.6 (2018): 1452-1459.

9. Rai J., et al. "Recent advances in antibacterial drugs". IJABM 3.1 (2013): 3-10.

10. Damanjit C S. "Synthesis and biological evaluation of 1,3-thiazines: A review". Pharmacophore 4.3 (2013): 70-88.

11. Vincent G., et al. "A Review on Biological Activities of Thiazine Derivatives". International Journal of Pharmaceutical Chemistry and Chemical Science 3 (2014): 341-348.

12. Pluta K., et al. "Recent progress in biological activities of synthesized phenothiazines". European Journal of Medicinal Chemistry 46 (2011): 3179-3189.

13. Harrison CJ and Bratcher D. "Cephalosporins: A Review”. Pediatric Review 29 (2008): 264-273.

14. Pfeifer Y., et al. "Resistance to cephalosporins and carbapenems in Gram-negative bacteria pathogens". International Journal of Medical Microbiology 300 (2010): 371-379.

15. Yadav LDS., et al. "Mercaptoacetic acid based expeditious synthesis of polyfunctionalised 1, 3-thiazines". Tetrahedron 6 (2005): 10013-10017.
16. Edayadulla N and Ramesh P. "Synthesis of 2, 6-dicarbethoxy-3, 5-diaryltetrahydro-1, 4-thiazine-1,1-dioxide derivatives as potent anticonvulsant agents". European Journal of Medicinal Chemistry 106 (2015): 44-49.

17. Zia-ur-Rehman M., et al. "A facile synthesis of novel biologically active 4-hydroxy-N0- (benzylidene)-2H-benzo (e) $(1,2)$ thiazine-3-carbohydrazide 1, 1-dioxides". European Journal of Medicinal Chemistry 44 (2009): 1311-1316.

18. Patel C., et al. "Synthesis and Antimicrobial Activity of 1,2-Benzothiazine Derivatives". Molecules (2016): 21.

19. Aurelija Urbanaite. "Synthesis of $4 \mathrm{H}$-thiazine". Chemistry of Heterocyclic Compounds 52 (2016): 1.

20. Jupudi S. "An overview on versatile molecule 1, 3- thiazine". Asian Journal of Research in Pharmaceutical Sciences 3.1 (2013): 170-177.

21. Sallal ZA. "Synthesis and characterization of new oxazine, thiazine and pyarazole derived from chalcone". Baghdad Science Journal 11 (2014): 2.

22. Koketsu M., et al. "Synthesis of 1,3-thiazine derivatives and their evaluation as potential antimycobacterial agents". European Journal of Pharmaceutical Sciences 15 (2002): 307-310.

23. Thansu J., et al. "Synthesis, spectral characterization and in vitro antibacterial and antifungal activities of novel 1,3-thiazine2-amines comprising morpholine nucleus". Journal of Enzyme Inhibition and Medicinal Chemistry 25.6 (2010): 756-764.

24. Kai H., et al. "2-Arylimino-5, 6-dihydro-4H-1,3-thiazines as a new class of cannabinoid receptor agonists. Part 3: synthesis and activity of isosteric analogs". Bioorganic and Medicinal Chemistry Letters 18.24 (2008): 6444-6447.

25. Aktay G., et al. "Synthesis of some 1, 2, 4-triazolo [3, 2-b]-1,3thiazine-7-ones with potential analgesic and anti-inflammatory activities". Farmaco 57.2 (2002): 145-152.

26. Jagodzinska E., et al. "Synthesis and biological activity of certain novel derivatives of $1 \mathrm{H}$-pyrrolo[1, 2-c][1,3] thiazine". Acta Poloniae Pharmaceutica 60.1 (2003): 67-74.

Citation: Khan Sana., et al. "Design, Synthesis and Antimicrobial Activities Evaluation of 1, 3 Thiazine Derivatives". Acta Scientific Pharmaceutical Sciences 5.7 (2021): 141-158. 
27. Cohen E., et al. "Photostabilization of nitromethylene heterocycle insecticide on the surface of montmorillonite". Clay and Clays Material 36.2 (1988): 159-164.

28. Bourzat JD., et al. "Perhydro 1,3-thiazine derivatives". U.S. patent (1981): $4271156 \mathrm{~A}$.

Volume 5 Issue 7 July 2021

(C) All rights are reserved by Khan Sana., et al. 